\title{
KORELASI RASIO CROSS SECTIONAL AREA MUSCULUS MULTIFIDUS LUMBAL MENGGUNAKAN ULTRASOUND DENGAN DERAJAT NYERI BERDASARKAN VISUAL ANALOGUE SCALE (VAS) PADA PASIEN NYERI PUNGGUNG BAWAH
}

\section{CORRELATION RATIO CROSS SECTIONAL AREA MUSCULUS MULTIFIDUS LUMBAL USING ULTRASOUND WITH DEGREE OF PAIN BASED ON VISUAL ANALOGUE SCALE (VAS) IN PATIENTS WITH LOWER BACK PAIN}

\author{
Jimmy Tungka*, Muhammad Ilyas, Bachtiar Murtala \\ Departemen Radiologi Fakultas Kedokteran, Universitas Hasanuddin, Jalan Perintis \\ Kemerdekaan Km.10, Makassar
}

\begin{abstract}
ABSTRAK
Nyeri punggung bawah (NPB) merupakan suatu sindroma klinik yang ditandai dengan gejala utama nyeri di daerah punggung bagian bawah yang dapat merupakan nyeri lokal maupun nyeri radikular ataupun keduanya. Peran otot-otot paraspinal lumbal sebagai penyebab NPB masih belum jelas. Otot-otot paraspinal lumbal ini berperan saat menerima beban saat tubuh bergerak dan saat menumpu berat badan. Ada indikasi bahwa musculus multifidus lumbal (LMM) merupakan otot paraspinal yang sensitif terhadap parubahan patologis yang berbeda pada tulang belakang lumbal dibandingkan otot paraspinal lainnya. Pengukuran musculus multifidus lumbal menggunakan ultrasound dapat memberikan penilaian yang tepat untuk menilai cross sectional area (CSA) otot. Penelitian ini bertujuan mengetahui korelasi rasio CSA muskulus multifidus lumbal menggunakan USG gray scale terhadap nyeri berdasarkan VAS. Penelitian dilaksanakan di Bagian Radiologi RSUP Dr. Wahidin Sudirohusodo Makassar pada Juli-Agustus 2018. Desain penelitian observasional dengan rancangan cross sectional. Sampel sebanyak 38 orang dengan gejala klinis nyeri punggung bawah radikular. USG gray scale dilakukan untuk mengukur CSA muskulus multifidus pada level dan sisi yang nyeri dan pada sebelahnya, kemudian dihitung rasionya. Hal yang sama dilakukan pada level di atas nyeri. Data dianalisis menggunakan uji korelasi Spearman dan Pearson. Hasil penelitian menunjukkan rerata sampel dengan derajat nyeri mild berdasarkan VAS. Mean rasio CSA yang diperoleh $81 \%$ pada level nyeri dan $82 \%$ pada level di atas nyeri. Terdapat korelasi antara rasio CSA muskulus multifidus lumbal pada level nyeri dan di atas nyeri terhadap derajat nyeri dengan arah korelasi negatif dengan nilai $p=0,001$ dan $p=0,002$. Semakin berat derajat nyeri, semakin kecil rasio CSA-nya.

Kata kunci: cross sectional area muskulus multifidus lumbal, USG gray scale, visual analogue scale
\end{abstract}




\begin{abstract}
Lower back pain (LBP) is a clinical syndrome characterized by the main symptoms of pain in the lower back region which can be local pain or radicular pain or both. The role of the lumbar paraspinal muscles as the cause of LBP is still unclear. The lumbar paraspinal muscles play a role when receiving a load when the body moves and when it restores weight. There are indications that lumbar musculus is a paraspinal muscle that is sensitive to different pathological changes in the lumbar spine compared to other paraspinal muscles. Measurement of lumbar multifidus musculus using ultrasound can provide an appropriate assessment to assess cross sectional muscle area. This research aimed to investigate the correlation between ratio of cross sectional area (CSA) of musculus multifidus lumbal using gray scale USG and the degree of pain based on VAS. The research was conducted in Radiology Department of Dr. Wahidin Sudirohusodo Hospital, Makassar from July-August 2018. The research was observational study with the cross sectional design. The total of 38 samples who suffered from the clinical pain in radicular lower back. The examination with gray scale USG was carried out in order to measure the CSA of musculus multifidus at the painful side and the other side; after that, the ratio was calculated. The same was done to the level above the pain. The data were then analyzed using Spearman and Pearson's correlation tests. The research result indicated that the mean of the research had experienced the degree of the mild pain based on the VAS. The mean ratio of the CSA was $81 \%$ in the pain level and $82 \%$ in the level above the pain. There was a significant correlation between the ratio of the CSA of musculus multifidus lumbal at the pain level and at the above pain level with the direction to the negative correlation of the value of $p=0.001$ and $p=0.002$. The heavier the degree of pain, the smaller the ratio of its CSA
\end{abstract}

Keywords: cross sectional area of musculus multifidus lumbal, gray scale USG, visual analogue scale

\footnotetext{
Penulis korespondesi:

Jimmy Tungka

Departemen Radiologi, Fakultas Kedokteran Universitas Hasanuddin

Jl.Perintis Kemerdekaan Km. 10, Makassar

Email: jimmy tungka80@yahoo.com
}

\title{
PENDAHULUAN
}

Nyeri punggung bawah (NPB) merupakan problematika yang banyak ditemukan dan sangat mengganggu aktivitas sehari-hari. Sebesar $60 \%-80 \%$ dari populasi di dunia pernah mengalami NPB terutama pada usia 25-55 tahun. Penyebab NPB dapat diklasifikasikan menjadi NPB akibat kondisi mekanik sebesar $98 \%$ dan NPB akibat penyakit visceral sebesar 2\% (Tian \& Qi, 2010; Deyo, 2000; Aulina, 2003).

Etiologi NPB diantaranya adalah ketegangan otot lumbal, sindrom lumbal zygapophysial joint, ketidakstabilan tulang belakang lumbal, nyeri punggung diskogenik, sindrom sendi sakroiliaka dan hernia nucleus pulposus (HNP). Menurut The Healthy Back Institute (2010), daerah lumbal merupakan daerah vertebrae yang sangat peka terhadap terjadinya nyeri punggung karena daerah lumbal paling besar menerima beban saat tubuh bergerak dan saat menumpu berat 
badan. Peran otot-otot paraspinal sebagai penyebab dari NPB masih belum jelas. Ada indikasi bahwa musculus multifidus lumbal merupakan otot paraspinal yang sensitif terhadap parubahan patologis yang berbeda pada tulang belakang lumbal dibandingkan otot paraspinal lainnya. Hides et al (1994) menunjukkan pengurangan luas penampang musculus multifidus lumbal di sisi ipsilateral pada pasien dengan NPB unilateral.

Musculus multifidus lumbal diinervasi oleh satu nerve root, tiap lapisan musclus multifidus menerima innervasinya hanya dari ramus dorsal. Jadi nervus multifidus yang berinervasi pada processus spinosus yang sama mendapatkan inervasi yang sama dari ramus dorsal cabang medial yang sama. Hal inilah yang menjelaskan mengapa terjadi atropi otot musculus multifidus pada level di atas nyeri (Jung II Kang,2013)

Pencitraan ultrasound muskulus multifidus lumbal sangat menarik perhatian Fisioterapis, baik untuk penelitian ataupun untuk kepentingan klinis. Secara klinis, penggunaan ultrasound diperuntukkan sebagai modalitas untuk mendeteksi abnormalitas dan memantau perubahan otot setelah terapi (Hides et al, 1994).

VAS adalah suatu instrument yang sering digunakan untuk menentukan intensitas dan frekuensi nyeri pada pasien dengan menggunakan skala dari tanpa nyeri hingga nyeri yang sangat hebat. VAS ini telah digunakan secara luas pada populasi dewasa. (Gillian et al,2011)

Qiunchen Huang et al (2014) melakukan penelitian untuk mengevaluasi nyeri punggung bawah dengan menilai rasio CSA musculus multifidus lumbal pada area yang sakit terhadap sisi sebelahnya pada level L5 menggunakan ultrasound kemudian dihubungkan dengan VAS. VAS dan rasio CSA musculus multifidus lumbar berkorelasi linear.

Hingga saat ini belum pernah dilakukan penelitan untuk mengetahui korelasi rasio CSA musculus multifidus lumbal menggunakan ultrasound gray scale terhadap derajat nyeri berdasarkan VAS. Penelitian ini bertujuan untuk mengetahui korelasi rasio CSA musculus multifidus lumbal menggunakan ultrasound gray scale terhadap derajat nyeri berdasarkan VAS. (Quinchen Huang et al,2014)

\section{METODE PENELITIAN}

Pengumpulan data penelitian ini dilakukan di Departemen Radiologi RSUP Dr.Wahidin Sudirohusodo Makassar dengan waktu penelitian dari bulan Juli hingga Agustus 2018. Populasi penelitian ini adalah semua pasien yang memenuhi kriteria inklusi dan eklusi. Kriteria inklusi adalah: penderita dengan keluhan nyeri punggung bawah kronik, yaitu nyeri yang berlangsung lebih dari atau sama dengan 12 minggu; umur kurang dari atau sama dengan 40 tahun; keadaan umum baik dan dapat menjalani pemeriksaan USG; bersedia mengikuti prosedur penelitian dengan mengisi informed concent. Sedangkan kriteria eksklusi adalah: keadaan umum pasien tidak memungkinkan untuk dilakukan pemeriksaan USG Lumbosacral; atlet olahraga (yang melakukan aktivitas olahraga minimal empat kali seminggu); pekerja berat (buruh); pernah menjalani operasi tulang belakang; riwayat trauma pada tulang belakang; kelainan perkembangan / scoliosis; kelainan kongenital tulang belakang; infeksi pada tulang belakang; tumor pada tulang belakang; pasien dengan tetraparese dan paraparese; riwayat urolitiasis; riwayat massa ginekologik; pasien yang pada pemeriksaan USG ditemukan atropi pada musculus multifidus kanan dan kiri.

Metode pengambilan data menggunakan consecutive sampling. Penelitan menggunakan Ultrasonography GE Logic E9 tahun 2017. Data yang diperoleh kemudian diolah secara computerized. Variabel yang dikorelasikan dibuat dalam kelompok numerik dan kategorik. Uji yang digunakan adalah uji Spearman dan Pearson. 


\section{HASIL DAN PEMBAHASAN}

Telah dilakukan penelitian terhadap 38 subyek , laki-laki 22 orang dan perempuan 16 orang dengan karakteristik sebagai berikut :

\begin{tabular}{lccc}
\hline & Minimun & Maximum & Mean \\
\hline Umur & 19 & 40 & 30.03 \\
\hline IMT & 15.8 & 31.3 & 21.4 \\
\hline
\end{tabular}

Tabel I. Distribusi sampel penelitian berdasarkan derajat nyeri VAS

\begin{tabular}{lcc}
\hline VAS & N & \% \\
\hline Severe & 8 & 21,1 \\
Moderate & 11 & 28,9 \\
Mild & 19 & 50,0 \\
\hline Total & 38 & 100,0
\end{tabular}

Sumber : Data Primer. Keterangan; N=jumlah sampel, \% = persentase

Tabel I terlihat frekuensi dan persentase derajat nyeri sampel berdasarkan VAS pada keseluruhan sampel. Hasilnya menunjukkan jumlah sampel pada kelompok nyeri severe sebanyak 8 orang $(21,1 \%)$ sampel, kelompok nyeri moderate dengan jumlah 11 orang $(28,9 \%)$ dan kelompok nyeri mild dengan jumlah 19 orang $(50,0 \%)$.

Tabel II. Distribusi sampel penelitian berdasarkan ratio CSA musculus multifidus lumbal pada lokasi Nyeri dan Rasio CSA musculus multifidus lumbal pada lokasi di atas nyeri

\begin{tabular}{lcccc}
\hline & Min & Max & Mean & SD \\
\hline Rasio CSA level nyeri & 66 & 99 & 81 & 8,6 \\
Rasio CSA level atas nyeri & 65 & 98 & 82 & 9,1
\end{tabular}

Sumber: Data Primer. Keterangan ; Min : Nilai minimal, Max : Nilai maximal, Mean = rata-rata,$S D=$ standar deviation

Pada tabel II menunjukkan ratio CSA musculus multifidus lumbal terendah adalah $66 \%$ dan ratio CSA musculus multifidus lumbah tertinggi adalah $99 \%$ dengan nilai rata-rata $81 \%$. Ratio CSA musculus multifidus lumbal terendah adalah $65 \%$ dan ratio CSA musculus multifidus lumbal tertinggi adalah $98 \%$ dengan nilai rata-rata $82 \%$. 
Tabel III. Distribusi rasio CSA musculus multifidus lumbal pada level nyeri dan level di atas nyeri berdasarkan derajat nyeri VAS

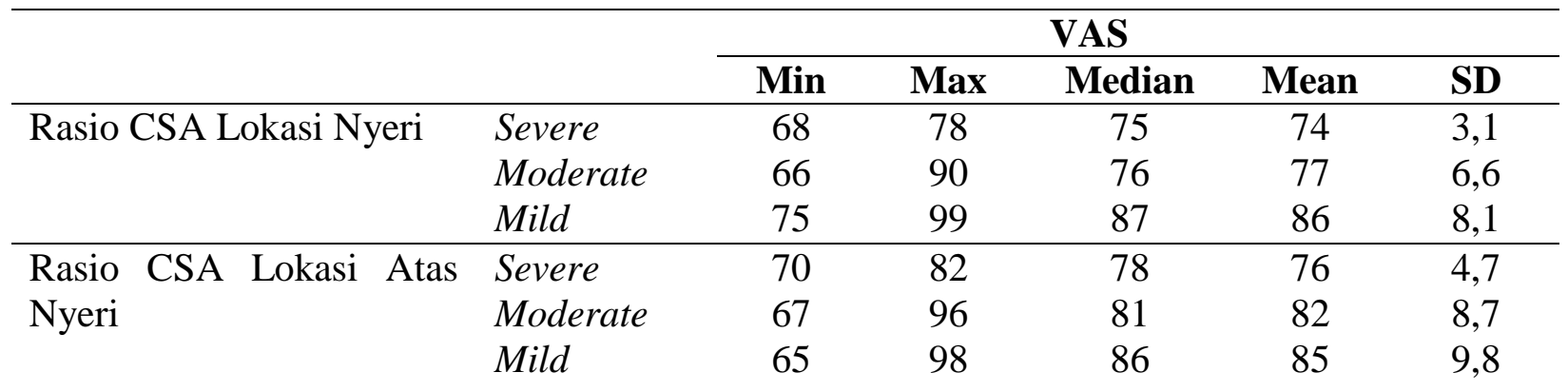

Sumber: Data Primer. Keterangan: Min: nilai minimal, Max: nilai maximal, $\quad$ Mean = rata-rata, $S D=$ standar deviation

Pada tabel III terlihat rasio CSA pada level nyeri dengan derajat nyeri severe mempunyai nilai minimal $68 \%$, nilai maksimal $78 \%$ dengan nilai median $75 \%$, mean $74 \%$ dan standar deviasi $3,1 \%$.

Rasio CSA pada level nyeri dengan derajat nyeri moderate mempunyai nilai minimal $66 \%$, nilai maksimal $90 \%$ dengan nilai median $76 \%$, mean $77 \%$ dan standar deviasi $6,6 \%$.

Rasio CSA pada level nyeri dengan derajat nyeri mild mempunyai nilai minimal $75 \%$, nilai maksimal 99\% dengan nilai median $87 \%$, mean $86 \%$ dan standar deviasi $8,1 \%$

Rasio CSA pada level di atas nyeri dengan derajat nyeri severe mempunyai nilai minimal $70 \%$, nilai maksimal $82 \%$ dengan nilai median $78 \%$,

Tabel IV. Korelasi rasio CSA musculus multifidus lumbal pada level dan sisi nyeri dengan VAS

\begin{tabular}{lcc}
\hline & \multicolumn{2}{c}{ VAS } \\
\cline { 2 - 3 } & Nilai $\boldsymbol{p}$ & $\mathbf{R}$ \\
\hline CSA level nyeri & 0,001 & $-0,67$ \\
\hline
\end{tabular}

Sumber : Data primer. Keterangan; p:spearman rho, $r$ : significant

Pada tabel IV terlihat korelasi CSA level nyeri dengan derajat nyeri berdasarkan VAS mempunyai korelasi yang bermakna dengan nilai $p=0,001$

Tabel V. Korelasi antara rasio CSA musculus multidus lumbal lokasi di atas nyeri dengan VAS

\begin{tabular}{lrc}
\hline & \multicolumn{2}{c}{ VAS } \\
\cline { 2 - 3 } & Nilai $\boldsymbol{p}$ & $\mathbf{R}$ \\
\hline CSA level atas nyeri & 0,012 & $-0,403$ \\
\hline
\end{tabular}

Sumber : Data primer. Keterangan; : spearman rho, $r$ : significant

Pada tabel V terlihat korelasi CSA level diatas nyeri dengan derajat nyeri berdasarkan VAS mempunyai korelasi yang bermakna dengan nilai $p=0,012$ 
Laki-laki secara signifikan memiliki ukuran CSA musculus multifidus lumbal yang lebih besar dibandingkan perempuan. Ukuran CSA akan ditemukan lebih besar pada L5 dibandingkan L4 (Stokes M.,2005)

Secara fisiologis usia sangat mempengaruhi massa otot seseorang. Sarcopenia adalah penurunan massa otot yang disebabkan oleh factor usia. Penurunan massa otot sangat mempengaruhi kualitas hidup manusia. Perubahan otot secara mikroskopis dan makroskopis dapat terjadi karena usia, nutrisi, perubahan hormon, penggunaan obat-obatan dan banyak hal lainnya. Karena hal ini maka pada penelitian ini dilakukan pada usia muda dengan harapan faktor usia tua yang dapat menyebabkan atropi musculus multifidus belum terjadi. (Patrick N, 2014)

Hasil uji Spearman menunjukkan korelasi antara CSA musculus multifidus lumbal pada level dan sisi nyeri dengan derajat nyeri berdasarkan VAS $(p=0,001$; correlation coefficient 0,667). Hasil tersebut bermakna bahwa terdapat korelasi yang kuat antara CSA musculus multifidus lumbal pada level dan sisi nyeri dengan derajat nyeri berdasarkan VAS. Semakin tinggi derajat nyeri berdasarkan VAS ditemukan rasio CSA yang semakin mengecil. Hal ini sesuai dengan penelitian sebelumnya yaitu terjadi atropi yang berat dari musculus multifidus pada level dan sisi nyeri (Freeman dan Woodham, 2010).

Jung-II kang melaporkan atropi fokal dan penggantian oleh lemak pada muculus multifidus lumbal sisi kanan menggunakan CT dan MRI pada level L5 pada pasien dengan keluhan klinis nyeri radiculopathy pada L5 (Jung II kang, 2012)

Hasil uji Spearman menunjukkan korelasi antara CSA musculus multifidus lumbal pada level dan sisi di atas nyeri dengan derajat nyeri berdasarkan VAS ( $p=0,012$; correlation coefficient 0,403. Hal itu menunjukkan bahwa CSA musculus multifidus lumbal pada level dan sisi di atas nyeri berkorelasi dengan derajat nyeri berdasarkan VAS dengan tingkat korelasi sedang. Semakin tinggi derajat nyeri berdasarkan VAS ditemukan rasio CSA yang semakin mengecil. Hal ini sesuai dengan penelitian sebelumnya yang dilakukan oleh Stokes et al yang menemukan CSA yang ikut mengecil pada level diatas nyeri.(Stokes et al,2005)

\section{KESIMPULAN}

Terdapat korelasi antara rasio CSA muskulus multifidus lumbal pada level nyeri dan di atas nyeri terhadap derajat nyeri dengan arah korelasi negatif. Semakin berat derajat nyeri, semakin kecil rasio CSA-nya.

\section{UCAPAN TERIMAKASIH}

Terimakasih kepada Departemen Radiologi RSUP Dr.Wahidin Sudirohusodo, Makassar, Indonesia yang telah memberikan kesempatan bagi peneliti untuk melakukan pengambilan data penelitian.

\section{DAFTAR PUSTAKA}

Aulina, S. 2003. Patofisiologi nyeri pinggang bawah dalam nyeri punggung bawah. Kelompok studi nyeri perhimpunan dokter spesialis saraf Indonesia. PERDOSSI ; 5-15.

Freeman, M.D, Mark A.Woodham, M.A., Andrews W., Woodham,BA. 2010. The role of the multifidus in chronic low back pain: a review. American Academy of Physical Medicine and Rehabilitation 2:142-146. Available at https://www.ncbi.nlm.nih.gov/pubmed/20193941 
Gillian A.Hawker, Samra Mian, Tetyana Kendzerska, Melissa French, Measures of Adult Pain.2011. Available online at https://www.ncbi.nlm.nih.gov/pubmed/22588748

Jung-II kang, Sun-Yu Kim Jin-Hyun Kim, Hyun Bang. The location of multifidus atrophy in patients with a single level, unilateral lumbar radiculopathy. 2013. Availabe online et https://www.ncbi.nlm.nih.gov/pubmed/24020030

Hides, J. A., Stokes, M.J., Saide, M., Jull, G.A., Cooper, D.H. 1994. Evidence of lumbar multifidus muscle wasting ipsilateral to symptoms in patients with acute/subacute low back pain. Spine 19; 165-172. Available at https://www.ncbi.nlm.nih.gov/pubmed/8153825

Quinchen Huang, Yuying Zhang, DeshengLt, Degang Yang, Ming Hio, et al. 2014. The evaluation of chronic low back pain by determining the ratio of the lumar multifidus muscle cross sectional areas of the unaffected and affected sides. Journal of physical therapy science, available on line at https://www.ncbi.nlm.nih.gov/pubmed/25364126

Stokes M., G.Rankin, D.J.Newham, 2005. Ultrasound imaging of lumbar multifidus muscle: normal reference ranges for measurements and practical guidance on technique, available online at https://www.researchgate.net/publication/7820081_Ultrasound_ imaging_of_lumbar_multifidus_muscle_Normal_reference_ranges_for_measurements_a nd_practical_guidance_on_the_technique

Patrick N.Siparsky, Donald T.Kirkendall, William E.Garrett. 2014, Muscle Changes in Aging, Understanding Sarcopenia, available on https:/www.ncbi.nlm.nih.gov/pmc/articles/ PMC3874224/

Simons DC, Travell J. Myofacial trigger points, a possible explanation (letter). Pain 1981;10:106109. Available at https://www.ncbi.nlm.nih.gov/pmc/articles/PMC4508225/

Tian, Wei., Qi, Hui. 2010. Associaton between intervertebral disc degeneration and disturbances of blood supply to the vertebrae. Chinese medical journal 123(2):239-43, available at https://www.researchgate.net/publication/41411892_Association_between_intervertebral_ disc_degeneration_and_disturbances_of_blood_supply_to_the_vertebrae 